\title{
Application of Infrared Spectroscopy to the Determination of Impurities in Titanium Tetrachloride ${ }^{1}$
}

\author{
Rolf B. Johannesen, Charles L. Gordon, James E. Stewart, and Raleigh Gilchrist
}

The infrared spectrum of pure titanium tetrachloride was measured in the range of 2 to 15 microns, and, by adding known amounts of certain substances, it was possible to identify the common impurities likely to be found in refined titanium tetrachloride and to establish their limits of detection. The application of infrared spectroscopy made possible a sensitive method of following the process of purification of the tetrachloride.

\section{Introduction}

In preparing titanium tetrachloride of high purity for fundamental research, it is necessary to be able to determine the over-all purity of the final product and to identify as well as to determine, the remaining impurities.

As the total amount of impurities will be small, one must use methods that are far more sensitive than ordinary chemical tests. To this end a number of physical methods may be employed, namely, the freezing and melting behavior of the substance, from which the over-all purity can be computed; emission spectroscopy and absorption spectroscopy in ultraviolet, visible, and infrared.

This paper describes the infrared absorption spectrum of titanium tetrachloride, the effect of certain impurities on the spectrum, and some techniques found useful in handling titanium tetrachloride.

\section{Spectrophotometer Cell}

The high reactivity of titanium tetrachloride with moisture and with many organic compounds presented special problems in the design and use of a suitable cell for holding the liquid during measurement. The most desirable cell would have been one constructed entirely of glass transparent to infrared light, capable of being evacuated, and filled by transfer in a high-vacuum system. Practically, it was necessary to use the customary rock-salt windows on a body of glass. Because the beam of radiation of the spectrophotometer (Perkin-Elmer, model 21) converges in passing through the sample, the cell was made in the shape of a truncated cone. Two types of cell were constructed, one with a long optical path, useful in the range of $2 \mu$ to $9.4 \mu$, and one with a short optical path, useful in the range of $9.4 \mu$ to $15 \mu$.

\subsection{Cell With Long Optical Path}

This cell, depicted in figure 1, was made from a 125 -ml Erlenmeyer flask by cutting off the bottom and a part of the neck. The first cut was made perpendicular to the axis of the flask at a point where the diameter was slightly less than 2 in. The second cut was made parallel to the first at a distance of $50 \mathrm{~mm}$. The cut edges were ground flat so that the distance between them was from 47 to $49 \mathrm{~mm}$, and were within 1 degree of being parallel.

${ }_{1}^{1}$ Financial support of this work was furnished by the Metallurgy Branch of the Office of Naval Research, Department of the Navy, Washington 25, D. C.
Attempts to fasten the rock-salt windows to the glass cell by pressure, using polyethylene or polytetrafluoroethylene gaskets, were unsuccessful. These gasketing materials were so hard that the windows could not be pressed tightly enough to prevent leaks without cracking the rock salt. Polychlorotrifluoroethylene wax proved workable, but it was soluble in the tetrachloride. The problem was solved very simply by sealing the rock-salt windows to the cell by means of a plasticized cellulose nitrate cement (Duco). This was done by coating the ends of the cell with the cement and pressing the windows against them. After a short setting period, the outside of each seal was coated with the cement, and later again coated. After allowing the cement to dry thoroughly, for a period of $48 \mathrm{hr}$, the cement was found to be inert to the titanium tetrachloride and could be left in contact with it for many days without causing any visible change, or adding any absorption bands to the spectrum. The only precaution necessary, other than to allow ample time for drying, was to keep the cement out of the path of the infrared beam.

A distinct advantage of this method of assembly was that the cell could be taken apart for cleaning and for repolishing of the windows, and then reassembled without altering the length of the optical path. This was accomplished by soaking the cell in acetone.

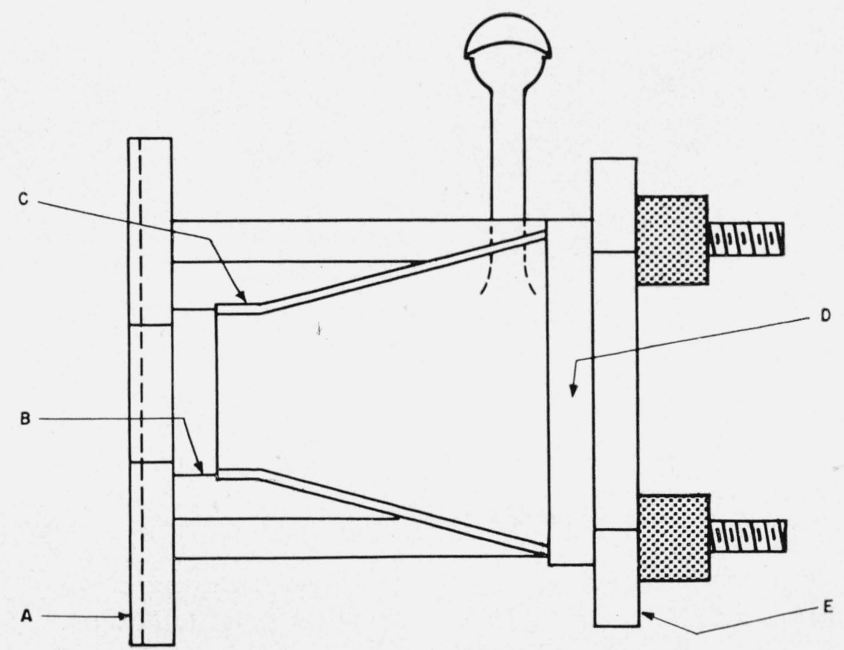

Figure 1. Cross section of 50- $\mathrm{mm}$ cell.

A, Cell holder frame; B, sodium chloride window; C, glass cell; D, sodium chloride window; E, clamp ring. 
Diametrically opposite sidearms were sealed close to the large end of the conical cell. The sidearms ended in standard spherical joints to which were fitted filling tubes and stopcocks.

The support and holder for the cell was composed entirely of brass and consisted of a $1 / 4$-in.-thick plate, 2 by 3 in., with edges milled to fit the Perkin-Elmer spectrophotometer cell clamp, at the center of which a hole, $13 / 16$ in. in diameter, was cut. Four $1 / 4$-in.posts, $3 \frac{1}{2}$ in. long, and threaded at the upper ends, permitted a $1 / 4$-in.-thick ring, $1 \frac{5}{8}$ in. in inside diameter and $2 \frac{3}{4}$ in. in outside diameter, to be pressed against the cell by four nuts with springs under them, when the cell was in position with the small window against the hole in the base plate.

\subsection{Cell With Short Optical Path}

The thin cell was constructed and assembled as shown in figure 2. The spacer, C, was made from polytetrafluoroethylene sheet of $0.25-\mathrm{mm}$ thickness. This was cemented between the two rock-salt windows. Two holes were drilled in window D, over which were cemented two filling tubes, F. Each filling tube had a slightly expanded diameter just inside a blind stem, which was inserted in one of the alining holes in the clamp ring, G. These filling tubes must have flat ends in the same plane. This was accomplished by inserting four filling tubes in the four inner holes shown in the ring at $\mathrm{G}$, and lapping them on a plate with fine emery. The two extra tubes were necessary to prevent rounding of the ends of the two to be used. By sealing a spherical joint on the end of each of tubes F, the thin cell could be mounted and filled in a manner identical with that for the large cell.

\section{Method of Filling the Cell}

Procedure A. To fill the cell with freshly distilled titanium tetrachloride, the arrangement depicted in figure 3 was devised. With tube B closed with a

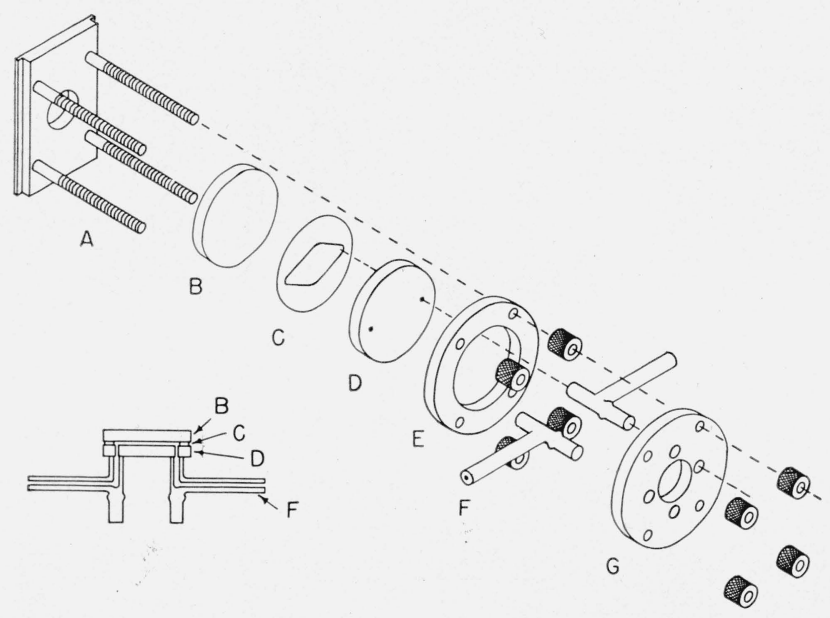

FIGURE 2. Thin ce!l (chamber thickness equal to thickness of spacer $C$ ).

A, Frame; B, window; C, spacer; D, window with filling holes; E, cell clamping ring; F, filling tubes; $G$, fllling tube clamping ring (also fitting tube grinding jig). rubber stopper, the system was evacuated to a pressure of $5 \mathrm{~mm}$ of mercury through a 2-way stopcock attached to joint L. Dry nitrogen was then admitted through $\mathrm{L}$ to a pressure of $1 \mathrm{~atm}$. The system was evacuated and filled with nitrogen 4 or 5 times, after which dry nitrogen was admitted to a pressure of 1 or $2 \mathrm{~mm}$ above atmospheric. At this stage the rubber stopper at B was removed, and the nitrogen allowed to flush through the system. While the flow of nitrogen continued, about $75 \mathrm{ml}$ of titanium tetrachloride was poured in through the sidearm, B, which was subsequently sealed with a flame, the flow of nitrogen being stopped as the sealing operation was completed. The system was then evacuated to a pressure of $120 \mathrm{~mm}$ and this pressure maintained by means of an adjustable leak at the pump.

The titanium tetrachloride in flask A was warmed gently to boil out dissolved gases. After the tetrachloride refluxed for a short time in section $\mathrm{C}$, it was distilled slowly. It was important that the distillate be kept cold at all times to prevent its condensation on the walls of the bell jar. The liquid distillate, caught in funnel $\mathrm{E}$, quietly ran into the cell. When the cell was full, the distillation was stopped, and flask A was cooled with tap water. Finally, dry nitrogen was admitted to the bell jar, the bell jar removed, and the stopcocks of the cell closed.

Procedure B. In determining the effect of impurities, the cell was filled by suction. To accomplish this, the portion of the apparatus in figure 3

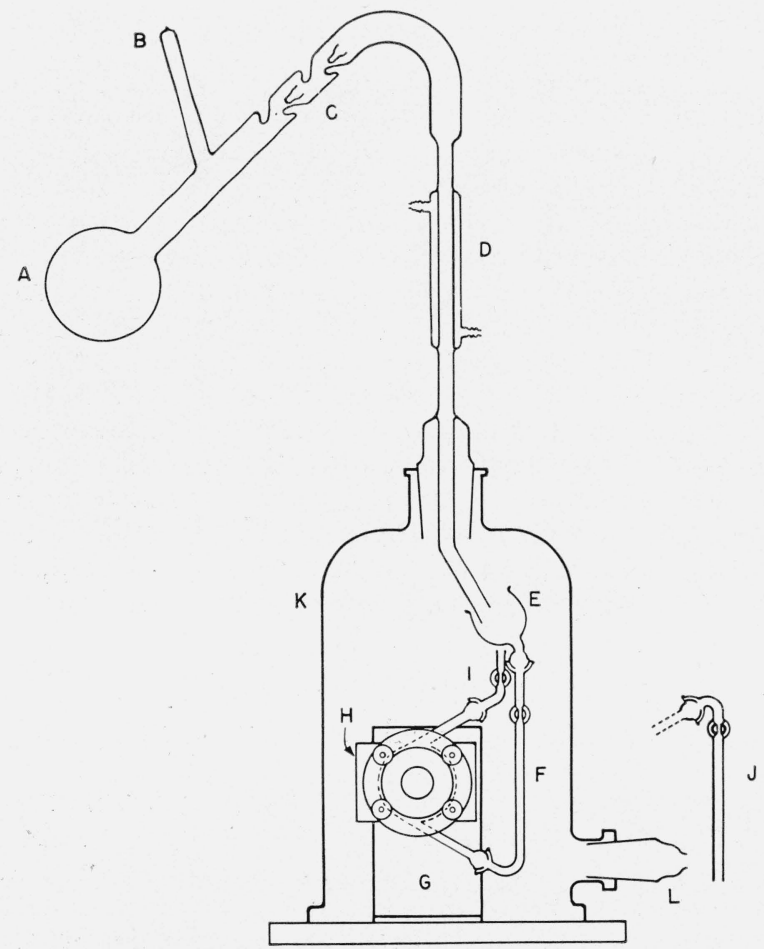

Figure 3. Apparatus for filling cell.

A, Distilling flask; B, filling tube; C, reflux condenser; D, delivery condenser; E, receiving funnel; $\mathrm{F}$, filling side-arm; $\mathrm{G}$, stand; $\mathrm{H}$, cell holder with cell; $\mathrm{I}$, venting side-arm; J, rinsing side-arm; $\mathrm{K}$, bell jar; $\mathrm{L}$, connection to vacu um and nitrogen. 
labeled F, G, H, and I was used. A two-way stopcock attached to vent tube I permitted air and moisture to be displaced from the cell by a current of helium. Reversing the stopcock allowed a sample of titanium tetrachloride to be drawn by vacuum into the cell through a glass tube attached to filling tube F. When the cell was filled, the stopcocks were closed, and the spectrum could be measured at once. After the measurement was completed, the titanium tetrachloride was blown into a waste flask by pressure of dry helium, and the cell was rinsed with three portions of dry carbon tetrachloride. The last drop of carbon tetrachloride rinse was evaporated in a stream of helium. The cell could then be refilled as described above. Bands of carbon tetrachloride were never found in the spectrum.

\section{Infrared Spectrum}

The absorption of infrared radiation was measured in the range from 2 to $15 \mu$ by means of a PerkinElmer model 21 double-beam recording spectrophotometer.

The titanium tetrachloride here involved was first chemically refined by W. Stanley Clabaugh, and then further purified by distillation in a highly efficient column by Robert T. Leslie of the Bureau. Description of the methods used will be given in a separate paper. The best titanium tetrachloride used in this work had an overall purity of 99.9991 mole percent, as measured by George T. Furukawa, of the Thermodynamics Section of the Bureau, by analysis of the melting curve. The spectrum of pure titanium tetrachloride appeared to be quite simple, showing only six broad absorption bands in the region from 2 to $15 \mu$. Table 1 shows the location of these absorption maxima and their absorbance indices.

The infrared spectrum is given in figure 4 .

The weak absorption at about $3 \mu$ arises from titanium dioxide deposited on the cell windows, and the weak sharp lines near $6 \mu$ are produced by uncompensated atmospheric water vapor. The weak sharp doublet near $3.5 \mu$ is due to hydrogen chloride (about $12 \mathrm{ppm}$ ), which was not entirely eliminated in filling the cell.

Infrared absorption spectra were measured for commercial samples of titanium tetrachloride as received and at successive steps in the purification process. Certain absorption peaks, present in the crudest material, disappeared from the spectrum after a simple distillation. No attempt to identify
TABLE 1. Infrared spectrum of titanium tetrachloride

\begin{tabular}{|c|c|c|}
\hline \multicolumn{2}{|c|}{ Absorption bands } & $\begin{array}{c}\text { Absorbance } \\
\text { index, } a\end{array}$ \\
\hline $\begin{array}{r}\mu \\
6.76 \\
7.35 \\
7.94 \\
9.00 \\
10.20 \\
11.16 \\
11.44\end{array}$ & $\begin{array}{r}c m^{-1} \\
1,479 \\
1,361 \\
1,259 \\
1,111 \\
980 \\
897 \\
874\end{array}$ & $\begin{array}{c}\mathrm{cm}^{-1} \\
0.058 \\
.125 \\
.033 \\
.056 \\
19.0 \\
\text { Shoulder } \\
19.8\end{array}$ \\
\hline \multicolumn{3}{|c|}{$a=\frac{1}{b} \log \frac{I_{0^{\mathrm{a}}}}{I}$} \\
\hline
\end{tabular}

a The symbols used are defined in "Spectrophotometry," NBS Circular 484, Sept. 15, 1949.

these peaks was made. Certain other peaks persisted, the wavelengths of which could be associated with

specific molecular groupings (e. g., $\quad \mathrm{C}=\mathrm{O}, \mathrm{H}-\mathrm{Cl}$ ).

The nature of the likely contaminants could be inferred from these peaks. Table 2 lists the absorption peaks and limits of detection of substances found to be persistent contaminants, or so reported in the literature.

TABLE 2. Characteristic infrared absorption peaks and limits of detection of common impurities in titanium tetrachloride

\begin{tabular}{|c|c|c|}
\hline Impurity & $\begin{array}{l}\text { Wavelength } \\
\text { of peak }\end{array}$ & $\begin{array}{l}\text { Limit of } \\
\text { detection }\end{array}$ \\
\hline $\begin{array}{l}\text { Hydrogen chloride, } \mathrm{HCl} \\
\text { Carbon dioxide, } \mathrm{CO} 2 \\
\text { Vanadium oxytrichloride, } \mathrm{VOCl}_{3} \\
\text { Phosgene, } \mathrm{COCl}_{2} \\
\text { Chloroacetyl chloride, } \mathrm{ClCH}_{2} \mathrm{COCl}\end{array}$ & $\begin{array}{l}\mu \\
3.53 \\
4.30 \\
4.84 \\
5.51 \\
5.55\end{array}$ & $\begin{array}{r}p p m \\
2 \\
? \\
40 \\
\text { about } 2 \\
0.5\end{array}$ \\
\hline $\begin{array}{l}\text { Dichloroacetyl chloride, } \mathrm{Cl}_{2} \mathrm{CHCOCl} \\
\text { Trichloroacetyl chloride, } \mathrm{Cl}_{3} \mathrm{CCOCl} \\
\text { Silicon tetrachloride, } \mathrm{SiCl}_{4} \\
\text { Hydrolysis product }\end{array}$ & $\begin{array}{l}5.55 \\
5.55 \\
8.14 \\
8.45\end{array}$ & $\begin{array}{l}1 \\
0.5 \\
200 \\
?\end{array}$ \\
\hline
\end{tabular}

No effort was made to ascertain the limits of detection for carbon dioxide or hydrolysis product, because both of these substances could be eliminated by a single careful distillation in an inert atmosphere or in a high vacuum. Qualitatively, the sensitivity was high as shown by the rapid increase in absorption at these wavelengths when the sample was exposed even briefly to ordinary air.

The limit of sensitivity is not good for either vanadium oxytrichloride or silicon tetrachloride by this method. Spectrophotometry in the visible region
FIGURE 4. Infrared spectrum of titanium tetrachloride. Curve A, 'measured in $50-\mathrm{mm}$ cell; curve B,
measured in 0.25 -mm cell.

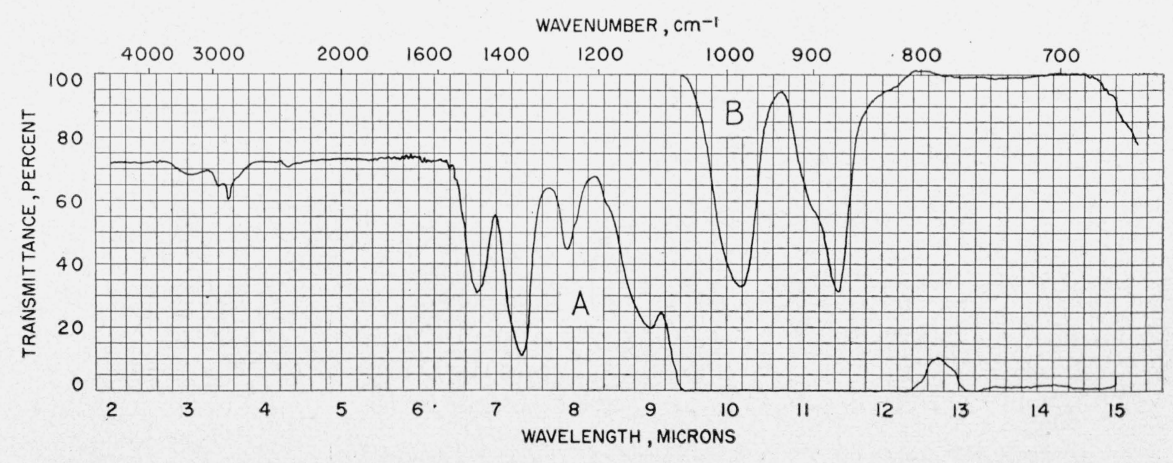


showed an intense absorption by vanadium oxytrichloride at $390 \mathrm{~m} \mu$, which caused a visible yellow color in concentrations as low as $1 \mathrm{ppm}$. Silicon compounds were determined by emission spectroscopy of an aqueous solution of the titanium tetrachloride, since infrared spectrophotometry proved too insensitive.

It is believed that this is the first time that chlorinated acetyl chlorides have been identified as persistent contaminants in commercial titanium tetrachloride. In very dilute solution, the three chlorides are indistinguishable spectrophotometrically. At somewhat higher concentrations (5 ppm), chloroacetyl chloride was found to have a second peak at $5.64 \mu$, which was about one-fourth as intense as the peak at $5.55 \mu$; dichloroacetyl chloride showed a second peak at $5.64 \mu$ of the same intensity as that at $5.55 \mu$. Trichloroacetyl chloride showed no secondary peaks in this range of concentrations. Whereas solutions of mono- and dichloroacetyl chlorides in titanium tetrachloride rapidly turn yellow, a solution of trichloroacetyl chloride (bp, $\left.118^{\circ} \mathrm{C}\right)$ at a concentration of 0.1 percent $(1,000 \mathrm{ppm})$ remains colorless for at least a week.

At no time in the course of these experiments was the characteristic hydroxyl absorption band at about $2.8 \mu$ observed. Apparently the reaction of titanium. tetrachloride with small amounts of water does not yield $\mathrm{Ti}(\mathrm{OH}) \mathrm{Cl}_{3}$, but instead a compound with a

$\mathrm{Ti}=\mathrm{O}$ or $-\mathrm{Ti}-\mathrm{O}-\mathrm{Ti}$ - linkage must be formed rapidly and completely on hydrolysis.

\section{Vibration Spectrum of Titanium Tetrachloride}

Except for the very early work of Marvin [1], ${ }^{2}$ there has been no infrared absorption spectrum reported for titanium tetrachloride. Numerous observations [2 to 8] of the Raman spectrum have established values for the fundamental vibrations, tabulated in table 3, and Rumpf [9] has reported very weak Raman lines, which perhaps correspond to harmonic or combination vibrations at 631.5, 784.5, and $926 \mathrm{~cm}^{-1}$, although these lines might arise from hydrolysis products.

TABLE 3. Fundamental vibrations from the Raman spectrum

\begin{tabular}{|c|c|c|c|c|}
\hline Worker and year & $\nu_{1}\left(a_{1}\right)$ & $\nu_{2}(e)$ & $\nu_{3}\left(f_{2}\right)$ & $\nu_{4}\left(f_{2}\right)$ \\
\hline $\begin{array}{l}\text { Daure [2] 1928 } \\
\text { Daure [3] 1929 } \\
\text { Trumpy [4] 1930 } \\
\text { Bhagavantam [5] 1930- } \\
\text { Cabannes and Rousset [6] } 1\end{array}$ & $\begin{array}{r}c m^{-1} \\
385 \\
390 \\
386 \\
382 \\
386\end{array}$ & $\begin{array}{r}c m^{-1} \\
113 \\
120 \\
119 \\
120 \\
120\end{array}$ & $\begin{array}{r}c m^{-1} \\
490 \\
500 \\
491 \\
494 \\
497\end{array}$ & $\begin{array}{r}\mathrm{cm}^{-1} \\
134 \\
140 \\
139 \\
145 \\
144\end{array}$ \\
\hline Delwaulle and François [7] & 389 & 120 & $\left\{\begin{array}{l}490 \\
506\end{array}\right.$ & 140 \\
\hline A verage values given by Kohlrausch [8] & 386 & 120 & 495 & 141 \\
\hline
\end{tabular}

Marvin's spectrum, which extended from 2 to $16 \mu$, excluded the fundamental region which lies beyond $20 \mu$ (below $500 \mathrm{~cm}^{-1}$ ). He reported bands at about $3160,1610,982,875$, and $822 \mathrm{~cm}^{-1}$ with considerable

\footnotetext{
2 Figures in brackets indicate the literature references at the end of this paper.
}

uncertainty, because of the doubtful sodium chloride dispersion data at his disposal. His sample was evidently quite impure.

Titanium tetrachloride has the symmetric tetrahedral structure [10] of point group $T_{d}$. Its fundamental vibrations are divided into symmetry species as follows: $1 a_{1}+1 e+2 f_{2}$. Only the two triply degenerate $f_{2}$ fundamentals are infrared active, but all are Raman active. Higher vibrational transitions must contain a component of species $F_{2}$ in order to be infrared active and a component of species $A_{1}, E$, or $F_{2}$ to be Raman active. Table 4 contains frequencies and assignments for bands observed in the present work and also for the three Raman lines reported by Rumpf. The frequencies given by Kohlrausch are used in calculating expected frequencies.

TABLE 4. Assignment of vibration frequencies of titanium tetrachloride

\begin{tabular}{|c|c|c|c|}
\hline \multirow{2}{*}{ Origin } & \multirow{2}{*}{ Symmetry species } & \multicolumn{2}{|c|}{ Wave number } \\
\hline & & Expected & Observed a \\
\hline $\begin{array}{l}\nu_{3}\left(f_{2}\right)+\nu_{4}\left(f_{2}\right) \\
2 \nu_{1}\left(a_{1}\right) \\
\left.\nu_{1}\left(a_{1}\right)+\nu_{3} ! f_{2}\right) \\
2 \nu_{1}\left(a_{1}\right)+\nu_{2}(e) \\
2 \nu_{1}\left(a_{1}\right)+\nu_{4}\left(f_{2}\right)\end{array}$ & $\begin{array}{l}A_{1}+E+F_{1}+F_{2} \\
A_{1} \\
F_{2} \\
E_{2} \\
F_{2}\end{array}$ & $\begin{array}{r}c m^{-1} \\
636 \\
772 \\
881 \\
892 \\
913\end{array}$ & \begin{tabular}{l}
\multicolumn{2}{c}{$\mathrm{cm}^{-1}$} \\
$631.5 \quad(\mathrm{R})$ \\
$784.5 \quad(\mathrm{R})$ \\
$874 \quad \mathrm{~S}$ \\
$897 \quad \mathrm{M}, \mathrm{SH}$ \\
$926 \quad(\mathrm{R})$
\end{tabular} \\
\hline $\begin{array}{l}2 \nu_{3}\left(f_{2}\right) \\
\nu_{2}(e)+2 \nu_{3}\left(f_{2}\right) \\
2 \nu_{1}\left(a_{1}\right)+\nu_{s}\left(f_{2}\right) \\
\nu_{1}\left(a_{1}\right)+2 \nu_{3}\left(f_{2}\right) \\
3 \nu_{3}\left(f_{2}\right)\end{array}$ & $\begin{array}{l}A_{1}+E+F_{2} \\
A_{1}+A_{2}+2 E+F_{1}+F_{2} \\
F_{2} \\
A_{1}+E+F_{2} \\
A_{1}+F_{1}+2 F_{2}\end{array}$ & $\begin{array}{r}990 \\
1,110 \\
1,267 \\
1,376 \\
1,485\end{array}$ & $\begin{array}{rl}980 & \mathrm{~S} \\
1,111 & \mathrm{VW} \\
1,259 & \mathrm{VW} \\
1,361 & \mathrm{VW} \\
1,479 & \mathrm{VW}\end{array}$ \\
\hline
\end{tabular}

${ }^{a}(\mathrm{R})$, Ramen line; S, strong; M, medium; VW, very weak; SH, shoulder.

The agreement between observed and calculated frequencies seems good in view of the uncertainties in the original Raman data. The two strongest bands in the infrared spectrum are assigned to the only two binary vibrations expected in this region. No bands assignable as difference combinations were observed, and no quaternary combinations were observed. $2 \nu_{1}+\nu_{2}\left(897 \mathrm{~cm}^{-1}\right)$ is of species $\mathrm{E}$ and should be infrared inactive. However, normally inactive bands are sometimes observed in spectra of liquids because of the perturbations produced by neighboring molecules.

\section{References}

[1] H. H. Marvin, Phys. Rev. 34, 161-186 (1912).

[2] Pierre Daure, Compt. rend. 187, 940-941 (1928).

[3] Pierre Daure, Ánn. phys. [10] 12, 375-441 (1929).

[4] B. Trumpy, Z. Physik 66, 790-806 (1930).

[5] S. Bhagavantam, Indian J. Phys. 5, 35-48; 59-71 (1930); \%, 79-86 (1932).

[6] J. Cabannes and A. Rousset, Ann. phys. [10] 19, 229-303 (1933).

[7] Marie-Louise Delwaulle and Félix Francois, Conpt. rend. 220, 173-174 (1945); J. Phys. Radium [8] 7, 15-32 (1946)

[8] K. W. F. Kohlrausch, Der Smekal-Raman Effekt, Ergänzungsband (Julius Springer, Berlin, 1938 ; Edwards Brothers, Ȧnn Árbor, Mich., 1944, p. 146).

[9] Marie-Elisa P. Rumpf, Compt. rend. 202, 950-952 (1936).

[10] G. Herzberg, Infrared and Raman spectra of polyatomic molecules (D. van Nostrand Co., Inc., New York, N. Y., 1945).

Washington, April 30, 1954. 